\title{
Integrating Authentic Contexts in Teaching the Indonesian as Foreign Language: An Eclectic Model for Vocabulary Instruction
}

\author{
Ani Rakhmawati \\ Sebelas Maret University \\ anirakhmawati@staff.uns.ac.id
}

\begin{abstract}
Authentic learning context is very important aspect for learner language acquisition, particularly to enhance learners' expressive skills for real communication. This paper discusses a model of vocabulary instruction which is integrated with reading an authentic text of current affair in Indonesia. For the teaching of Indonesian as second language, the need to use authentic material is a great challenge for either the teacher and the learners. Although resources and online multimedia can be easily accessed, however, selecting and organizing a comparably suitable topic for different learners' background in higher education need to be methodically prepared. By using multiple activities on teaching vocabulary through authentic reading material can develop student comprehension as well as their productive language skills. The eclectic model is developed to enhance the acquisition of new vocabularies through various tasks and reading activities. This eclectic teaching model is considerable handy choice to organize material using different methods and different techniques of different methods to serve different background of learners, age, gender, goal, either in short term and long term activities.
\end{abstract}

Keywords: vocabulary instruction, eclectic method, learning contex

\section{PENDAHULUAN}

Kosakata merupakan elemen yang sangat penting dalam pembelajaran bahasa. Bagi sebagian orang, memperoleh bahasa baru berarti sama halnya dengan mengetahui kata baru. Belajar kosakata baru harus diperoleh dan tertanam melalui konteks[1]. Dia tidak setuju bahwa belajar kosakata hanya didapat melulu dari menghafal daftar kata, kamus dan terjemahan langsung. Ini berarti bahwa pengajaran kosakata harus dilakukan dalam konteks yang bermakna, seperti dalam bentuk jurnal atau berita di koran atau majalah. Hal ini memerlukan pilihan metode pembelajaran yang dapat mendorong terjadinya komunikasi yang bermakna dengan penggunaan bahasa yang sesungguhnya.

Penerapan pengajaran kosakata mungkin berbeda berdasarkan tujuan belajar[2]. Dengan demikian, bahan ajar kosakata dapat bervariasi termasuk bentuk kata dasar, kata asal, kata turunan, kata berimbuhan, baik yang diucapkan maupun kata-kata tertulis. Dalam bahasa Indonesia, pengenalan bentuk kata dan perubahannya, baik kata asli maupun kata terjemahan, harus diintegrasikan ke dalam penggunaan bahasa yang bermakna. Untuk pembelajar yang berada di tingkat lanjut, bentuk kata yang lebih kompleks dapat dipertimbangkan sebagai bahan 
ajar, seperti makna konseptual dan asosiasi semantik dari kata yang dimaksud sampai ke kendala pemilihan gaya bahasa yang menentukan apakah kata tersebut sesuai dalam konteks tertentu.

Secara tradisional, konsep kosakata diajarkan melalui daftar kata-kata sulit dan kata-kata kompleks atau frasa yang rumit untuk mengetahui arti dari setiap kata. Namun secara umum diterima bahwa pembelajar dapat belajar kosakata dengan lebih efektif ketika mereka terlibat langsung dalam membangun makna kata dibandingkan dengan ketika pembelajar diminta untuk menghafal atau mengingat. Sebagian besar kosakata diperoleh melalui pembelajaran insidental di mana peserta didik terlibat langsung secara aktif dalam kegiatan pembelajaran bahasa [3]. Pengelompokan semantik dan tematik memiliki efek positif pada pembelajaran kosakata bahasa kedua [4]. Dengan demikian, strategi ini sama halnya dengan membuat pemetaan semantik dan membuat jaringan kata-kata yang melibatkan perspektif dan inisiatif pembelajar sendiri dalam menciptakan interaksi pernyataan atau kalimat yang bermakna di mana semua hal tersebut dilakukan dalam model ini. Dengan cara ini dimungkinkan digunakannya kombinasi pendekatan pengajaran langsung dan pembelajaran berbasis penemuan (discovery) dalam mempromosikan konteks otentik kepada pembelajar asing [5].

Mengingat latar belakang peserta didik yang heterogen, diperlukan metode pembelajaran yang fleksibel. Metode eklektik adalah pilihan yang sangat berguna untuk membantu dan menfasilitasi pembelajar belajar di tingkatan lebih lanjut. Model pengajaran eklektik dapat diusahakan dengan menggunakan metode dan teknik yang berbeda-beda, dengan mempertimbangkan perbedaan usia, jenis kelamin, tujuan belajar, baik dalam pembelajaran jangka pendek maupun jangka panjang [6]. Model yang berbeda-beda dapat memiliki kekuatan dan keterbatasan mereka sendiri [7]. Dengan model eklektik ini, mahasiswa asing tetap dapat menggunakan bahasa yang telah dipelajari sebelumnya atau telah diperoleh di masa lalu atau saat mereka berada di negara asal. Pengetahuan awal dan pengalaman pribadi pembelajar kemudian dikombinasi dan dimanipulasi sedemikian rupa untuk merangsang terjadinya pemerolehan kosakata baru.

Model eklektik ini bertujuan untuk meningkatkan kemampuan komunikatif mahasiswa asing dan memberikan pengayaan dengan pembelajaran berbasis tugas di mana pembelajar dapat langsung mengimplementasikan kegiatan dalam situasi seperti dalam komunikasi nyata kehidupan sehari-hari [8]. Model ini mempertimbangkan bagaimana peserta didik dapat menginternalisasi bahasa kedua yang sedang dipelajari dan bertujuan mencapai tujuan komunikatif peserta didik menggunakan bahasa yang sebenarnya [9]. Model ini memungkinkan untuk pengembangan fitur-fitur dalam pengajaran dan pembelajaran bahasa kedua yang dijelaskan oleh Brown, seperti: menekankan interaksi, menggunakan teks otentik, fokus pada proses belajar sendiri, meningkatkan pengalaman pribadi peserta didik, mengaktifkan bahasa di luar kelas, menekankan pada kontekstualisasi, dan fokus pada komunikasi yang efektif [10]. Oleh karena itu, penggunaan model eklektik ini akan memastikan bahwa fitur-fitur tersebut dapat diterapkan secara efektif melalui berbagai tugas khususnya aktivitas dalam kelompok kecil.

\section{METODE}

Kegiatan-kegiatan ini dipersiapkan dengan secara yang luwes yang memungkinkan mahasiswa dapat langsung mengakses ke laman atau direktori situs pemerintah, khususnya di komite pemilihan Indonesia. Akses ke Internet sangat dianjurkan untuk membantu pembelajar aktif terlibat dalam model ini. Dalam gaya belajar saat ini, kondisi ini merupakan usaha yang cukup mudah bagi semua orang untuk terlibat dalam banyak aktivitas, seperti melalui media sosial, menjalin bentuk komunikasi dan mengirim surat elektronik ke masyarakat Indonesia atau mencari berita terbaru tentang peristiwa terkini yang terjadi. Dalam penggunaan model eklektik 
ini, pembelajaran bahasa dan proses akuisisi kosakata difasilitasi melalui beberapa cara yang terdiri atas: (1) Memberikan input berupa berita dan situasi kekinian baik berupa gambaratau video dan bahan otentik lainnya; (2) Memberi kesempatan kepada mahasiswa untuk membagikan pendapat dan pengalaman mereka dengan penafsiran yang bermakna dan mengambil manfaat dari orang lain melalui kerja kelompok atau diskusi terstruktur;

a. Mendorong pembelajar untuk menebak menyimpulkan dan makna melalui penggunaan petunjuk kontekstual melalui aktivitas membaca berita;

b. Memberikan kesempatan menggunakan kreativitas bahasa mereka untuk berekspresi, baik melalui lisan maupun tulis, gagasan, hasil pemikiran dan pengalaman mereka sendiri.

c. Pembelajar diminta untuk mengerjakan kegiatan multi-tasking dengan bebas untuk berlatih berkomunikasi dengan penutur asli Bahasa Indonesia baik secara lisan maupun tulisan.

\section{HASIL DAN PEMBAHASAN}

Mengajar dan belajar bahasa Indonesia sebagai bahasa asing adalah hal yang unik. Banyak orang berpikir dengan sudut pandang yang berbeda dan dan model yang bervariasi. Pada dasarnya belajar Bahasa Indonesia tidak bisa dipisahkan dengan budaya, tradisi, dan peristiwa mutakhir di lingkungan politik dan pemerintahan Indonesia. Pada kenyataannya, sebagian mahasiswa asing lebih senang belajar tentang makanan dan kuliner Indonesia, karakter orang Indonesia dan tradisi mereka, dan juga masalah yang saat ini terjadi di Indonesia. Tiga aspek ini membuat guru mempertimbangkan situasi nyata yang cocok di dalam kelas. Tema masalah yang terjadi di Indonesia saat ini, yaitu pemilihan umum, dipilih untuk memperkuat model pengajaran eklektik karena berhadapan dengan mahasiswa dewasa yang segera berinteraksi dengan masyarakat luas di Indonesia.

Pengajaran kosakata ini disiapkan untuk pembelajar Bahasa Indonesia tingkat lanjut atau pelajar dalam tingkatan pendidikan tinggi, khususnya bagi pembelajar asing yang baru datang ke Indonesia untuk masuk dan belajar di universitas. Sebagai bagian dari kebijakan era terbuka, banyak universitas di Indonesia sekarang menyambut pembelajar dari seluruh dunia untuk belajar di Indonesia. Universitas Sebelas Maret di Surakarta adalah salah satu lembaga pendidikan tinggi yang membantu melayani pelatihan intensif khusus dan kursus pembelajar asing untuk meningkatkan penguasaan bahasa Indonesia mereka sebelum memasuki program pendidikan di universitas tujuan. Sebagai konsekuensinya, setiap tahun banyak pembelajar dari luar negeri, seperti dari Brasil, Amerika Serikat, Afrika Selatan, Prancis, Jepang, dan banyak negara lain, yang perlu mengikuti kursus singkat persiapan bahasa di Indonesia sebagai Bahasa Asing. Kursus ini bertujuan memberikan lebih banyak latihan dan rasa percaya diri bagi pembelajar dalam berkomunikasi di kondisi baru (negara baru).

Model kegiatan bahasa ini terutama dikembangkan untuk pengajaran berbasis kelas di mana guru bertanggung jawab atas seluruh kegiatan di kelas. Peran guru dalam pengajaran kosakata ini adalah sebagai fasilitator dan mitra diskusi pembelajar. Meskipun peserta didik individu mungkin dapat menggunakan kegiatan yang disediakan akan tetapi mereka akan mengalami kesulitan dalam menyelesaikan tugas mungkin terjadi selama waktu itu karena kekuatan strategi didasarkan pada interaksi kelompok. Latar belakang pembelajar yang beragam memang membutuhkan bantuan agar kursus singkat pembelajar dapat berjalan lancar dalam situasi yang lebih baik.

Kegiatan mahasiswa yang dilaksanakan melalui model eklektif ini sangat beragam tetapi bersifat fleksibel. Daftar kegiatan di bawah ini dapat menggambarkan padatnya aktivitas mahasiswa, misalnya sebagai berikut: 
1. Kegiatan 1: Curah pendapat (brainstorming) menggunakan pengetahuan sebelumnya tentang yang terjadi di Indonesia saat ini "Pemilu 2019".

2. Kegiatan 2: Bekerja dalam kelompok kecil untuk melengkapi word webbing dan pemetaan semantik sebagai bagian dari kegiatan pra-membaca.

3. Kegiatan 3: Membaca bahan bacaan "Pemilu yang Jurdil".

4. Kegiatan 4: Diskusi dengan seluruh anggota kelas (grup besar) untuk memahami bacaan tersebut.

5. Kegiatan 5: permainan akronim dan strategi pengumpulan kosakata baru (menggunakan permainan kata dan strategi hot-potato).

6. Kegiatan 6: Mensintesis melalui aktivitas lisan atau tertulis

7. Kegiatan 7: Menulis surat ke lembaga tertentu di Indonesia

Model ini akan bekerja lebih baik jika peserta didik sudah mempelajari pembentukan kata dalam bahasa Indonesia. Ini berarti bahwa kegiatan seperti word webbing dan mengidentifikasi kata harus dilakukan sebelum kegiatan membaca. Sebelum memasuki kegiatan inti, pembelajar disarankan untuk mengunjungi laman 'Indonesian Newspaper Directory' dan 'Pemilu 2019' yang dapat dikerjakan secara teratur di luar kelas. Sementara itu, untuk kegiatan sintesis menulis surat membutuhkan beberapa kali proses untuk meninjau kembali genre penulisan surat dan kepantasan berbasis tradisi di Indonesia, misalnya dalam membuka dan mengakhiri tulisan yang dimaksud.

Evaluasi dilakukan dalam berbagai langkah. Dalam hal ini, mempertimbangkan untuk mengevaluasi proses pembelajaran daripada menguji hasil akhir produk. Oleh karena itu, selama kegiatan belajar mengajar, evaluasi seperti mengajukan pertanyaan sederhana yang harus dijawab dengan kata sederhana, misalnya dilakukan untuk memeriksa pemahaman pembelajar tentang topik tersebut. Pada akhir model ini, peserta didik juga memiliki jenis evaluasi sumatif menggunakan berbagai cara dengan tugas yang lebih kompleks. Evaluasi yang disiapkan untuk pengajaran kosakata ini disusun berdasarkan teori teori Bahasa Indonesia dan cara berkomunikasi dalam situasi nyata dengan komunitas nyata.

Model ini memiliki potensi untuk mencapai tingkat interaksi dan komunikasi yang tinggi dalam menggunakan bahasa melalui curah pendapat (brainstorming) dan aktivitas kelompok kecil. Aktivitas kelompok kecil memberikan pembelajaran kooperatif dan kolaboratif tingkat tinggi yang akan meningkatkan interaksi yang tulus [11]. Keterlibatan peserta didik untuk menjadi percaya diri dalam mengambil risiko saat menggunakan bahasa kedua atau asing, pada gilirannya akan berbuah kompetensi komunikatif. Pembelajar didorong untuk menggunakan strategi apa pun untuk membantu mereka memahami makna kata-kata asing dan makna keseluruhan kalimat. Strategi ini, yaitu dalam menghindari gangguan komunikatif, diperlukan pelajar bahasa kedua untuk mencapai kompetensi linguistik, kompetensi sosiolinguistik, dan kompetensi gramatikal [12].

Keterlibatan pembelajar dalam kerja kelompok menawarkan berbagai cara untuk menyelesaikan masalah yang pembelajar miliki dalam memahami teks. Bekerja dalam kelompok membantu pembelajar memperkuat dan memperjelas pemahaman pembelajar tentang proses membaca. Pemanfaatan aktivitas dalam kelompok kecil dapat membantu mempromosikan pembelajaran kooperatif dan pembelajaran kolaboratif yang dianggap memberikan contoh bentuk komunikasi yang asli [13]. Selain itu, penggunaan kerja kelompok juga mempromosikan iklim afektif positif dan memotivasi pembelajar terlibat dalam menyelesaikan tugas.

Model ini juga memiliki kelebihan lain. Teks otentik dan realia dalam Bahasa Indonesia mempromosikan pemahaman budaya negara. Fitur bahasa dan budaya ini akan memberikan input yang komprehensif yang penting dalam mempelajari bahasa kedua. Selain itu, Krashen dan Terrel mengingatkan kita bahwa bahasa paling baik diajarkan ketika digunakan untuk 
mengirimkan pesan, bukan ketika diajarkan secara eksplisit untuk pembelajaran sadar [14]. Karena itu, menulis surat persuasif kepada Panitia Pemilihan Umum untuk membagikan ide atau saran sangat cocok sebagai kegiatan sintesis. Oleh karena itu, sepanjang model ini, kesadaran peserta didik terhadap masalah saat ini yang terjadi di negara target akan meningkatkan perolehan kosakata pembelajar. Penggunaan beragam metode untuk memfasilitasi peserta didik dalam mencapai kompetensi bahasa sudah sesuai dengan pandangan saat ini dalam pembelajaran bahasa [15] [16][17].

\section{SIMPULAN}

Model eklektik ini memberikan kontribusi yang bermanfaat bagi pembelajaran bahasa Indonesia sebagai bahasa asing. Tujuan utama dari penggunaan model eklekstik ini adalah untuk meningkatkan akuisisi kosakata baru agar mahasiswa asing dapat dengan cepat mampu berkomunikasi di lingkungan akademik secara efektif, baik lisan maupun tulis. Model ini juga bertujuan untuk memperkuat kemampuan pembelajar dalam mengenali berbagai pola kosakata Bahasa Indonesia, khususnya yang berkaitan dengan bentuk kata berimbuhan. Lebih lanjut lagi, mahasiswa juga dibekali dengan adanya kecenderungan penggunaan akronim dalam bahasa Indonesia yang berasal dari kata dasar (root), dan kompleks, seperti halnya reduplikasi, kata majemuk, dan kata-kata yang mengandung akar kata ditambah dengan afiks. Namun, melalui model ini, semua keterampilan berbahasa secara makro (mendengarkan, berbicara, membaca, dan menulis) akan meningkat secara merata. Artinya, selain pengetahuan kosakata yang cukup luas, pelajar akan terbantu dan dimudahkan dalam pemahaman teks baik lisan dan tulisan.

\section{REFERENCES}

[1]. Prince, P. Second language vocabulary learning: The role of context versus translation as a function of proficiency. The Modern Language Journal, 80 (4): 478-493, 1996.

[2]. Oxford, R. L. Cooperative learning, collaborative learning, and interaction: Three communicative strands in the language classroom. Modern Language Journal, 81 (4), 443-456, 1997.

[3]. Hatch, E. \& C. Brown. Vocabulary, semantic, and language education. Cambrigde: Cambrigde University Press, 1995.

[4]. Tinkham, T. The effects of semantic clustering the learning vocabulary. Second Language Research. 13 (2), 138-168, 1997.

[5]. Brown, C. Factors affecting the acquisition of vocabulary: frequency and saliency of the words. In T. Huckin, M. Haynes \& J. Coady (eds.) Seconds language reading and vocabulary learning (pp. 163-286). Norwood, NJ: Ablex Publishing. 1993.

[6]. Kumar, Ch. P. The Eclectic Method - Theory and Its Application to the Learning of English. International Journal of Scientific and Research Publications, 4 (3) 3, 1-4. 2013.

[7]. Larsen-Freeman, D. (2015). Techniques and Principles in Language Teaching. 3rd Edition. Oxford, Oxford University Press.

[8]. Long, M. H. \& Crookes, G. Three approaches to task-based syllabus design. TESOL Quarterly, 26 (1): 27-56. 1992.

[9]. Savigon, S. J. Communicative competence: Theory and classroom practice. (2 ${ }^{\text {nd }}$ Edition). Reading, M; Addisson-Wesley. 1997. 
[10]. Celce-Murcia, M., Dornyei, Z., Thurrell, S. Direct approaches in L2 instruction: A turning point in communicative language teaching. TESOL Quarterly, 31 (1), 141-152. 1997.

[11]. O'Malley, J. M. \& Chamot, A. Learning Strategies in Second language acquisition. Cambrigde Univerity Press. 1990.

[12]. Tarone, E. Teaching strategic competence in the foreign-language classroom. In S. J. Savigon \& M. S. Berns, Initiatives in communicative language teaching pp. 127-136. Reading, MA: Addison Wesley Publishing Company. 2004.

[13]. Ellis, R. Factors in the incidental acquisition of second language vocabulary from oral input: A review essay. Applied Language Learning, 5 (1), pp.1-32. 1994.

[14]. Krashen, S. \& Terrel, T. The natural Approach: Language acquisition in the classroom. New Jersey: Regents/Prentice Hall. 1983.

[15]. Kumaravadivelu, B. Understanding Language Teaching. ESL \& Applied Linguistics Professional Development. 2009.

[16]. K. Saddhono, Suhartatik, Bagiya, Widodo, and H. Wahyono, "Learning vocabularies using multimedia-based Teaching Indonesian to Speakers of Other Languages (TISOL)," in Journal of Physics: Conference Series, 2019, p. 012108.

[17]. K. Saddhono, A. Hasibuan, and M. I. Bakhtiar, "Facebook as A Learning Media in TISOL (Teaching Indonesian to Speakers of Other Languages) Learning to Support The Independency of Foreign Students in Indonesia," in Journal of Physics: Conference Series, 2019, vol. 1254, no. 1, p. 12061. 